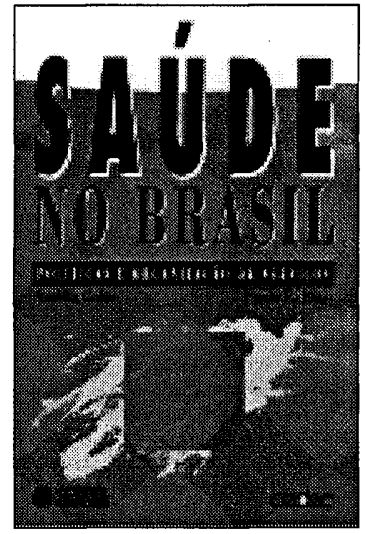

\title{
Em Busca da Justiça Social
}

Saúde no Brasil: Políticas e Organização de Serviços Amélia Cohn \& Paulo E. Elias.

São Paulo: Cortez, 1996.

117 páginas

José Mendes Ribeiro

Pesquisador-visitante do Convênio FIOCRUZ/FAPERJ.

Se quisermos saber no que consiste, precisamente, o maior de todos os bens, qual deva ser a finalidade de todos os sistemas de legislação, verificar-se-á que se resume nestes dois objetivos principais: a liberdade $e$ a igualdade. A liberdade, porque qualquer dependência particular corresponde a outro tanto de força tomada ao corpo do Estado, e a igualdade, porque a liberdade não pode subsistir sem ela (...). Tal igualdade, dizem, é uma quimera do espírito especulativo, que não pode existir na prática. Mas, se o abuso é inevitável, segue-se que não precisemos pelo menos regulamentá-lo? Precisamente por sempre tender a força das coisas a destruir a igualdade, a força da legislação deve sempre tender a mantê-la.

J.J. Rousseau - Do Contrato Social.

As sociedades no século XX enfrentam a busca pela igualdade, ou a minimização das desigualdades, por modos e mecanismos diferentes dos imaginados por pensadores do século XVIII, especialmente em função dos papéis reservados ao Estado para além da garantia da Lei e da
Ordem Social. De qualquer forma, as Leis de nosso século preservam a vocação redistributiva. Com o desenvolvimento do mercado como expressão dinâmica do capitalismo, as desigualdades foram perpetuadas e restou ao Estado, através das políticas, compensar, por recursos fis- cais e direcionamento de prioridades, tais "disfunções". A utopia de combinar mercado e justiça social no capitalismo compete com a herança marxista voltada a alterar o caráter de classe do Estado burguês. No debate político e sociológico contemporâneo, as atenções voltam-se à com- 
preensão e à busca de resolução dos conflitos entre alocação pública e privada.

No Brasil, em meados da década de 90, estas questões permanecem na ordem do dia. São tempos de reformas. Algumas delas, como a Reforma do Aparelho de Estado, influenciadas (pelo menos no plano da condução que tem sido dado pelo Governo FHC) pela crítica conservadora ao Estado de BemEstar europeu, fortalecida pelas duradouras vitórias eleitorais da década de 70 . Outras, como a da Seguridade Social, embora potencializada por este debate, pertencem a uma discussão de várias décadas sobre questões atuariais, de inclusão de clientelas e de eficiência de gestão, englobadas na chamada "Crise da Previdência". Outra reforma em voga é a da Saúde, mas esta tem antecedentes diferentes por ser caudatária e potencializada pela Reforma Sanitária dos anos 80 , inspirada e conduzida pelos ideais redistributivos da esquerda no Brasil.

Justamente a Seguridade Social e o Sistema Único de Saúde no Brasil são objeto de Amélia Cohn e Paulo Elias no oportuno lançamento da Editora Cortez, que nos chega às mãos. O livro, composto de dois textos integrados, destina-se, como assinalam os Autores, ao apoio a atividades didáticas no campo da Saúde Coletiva; porém, como não poderia deixar de ser em função do próprio perfil dos Autores, oferece uma visão própria sobre a história recente das políticas de Saúde e de Previdência Social. Esta análise busca, além de recuperar um fio condutor destas políticas, apontar as iniqüidades sociais, e alinhavar algumas alternativas para a readequação de objetivos e ações em busca da justiça social. A denúncia dos fracassos do Estado no Brasil em promover políticas redistributivas exitosas é a tônica do quadro analítico apresentado pelos Autores, além da apresentaçào e análise de dados recentes. O primeiro texto, de Amélia Cohn, trata de descrever e discutir os arranjos pós-Constituinte de 1988 no plano da Seguridade Social, considerado excludente e injusto. O texto de Paulo Elias trabalha dentro desta mesma lógica os eventos mais diretamente ligados à política de Saúde e a distribuição da oferta de serviços pelas diferentes redes de assistência pública.

No primeiro texto, "A Saúde na Previdência Social e na Seguridade Social: Antigos Estigmas e Novos Desafios", Amélia Cohn apresenta a engenharia política da criação da Previdência Social brasileira e a sua recolocação como fundamento da seguridade a partir da Constituinte de 1988. Estes dois eixos percorrem o conjunto do tex- to para sustentar a análise final acerca das políticas de saúde, em termos de recursos financeiros, arranjos institucionais e distribuição de serviços.

Começa pela montagem da Previdência Social no Brasil, a partir da Lei Eloy Chaves, de 1923, criando as Caixas de Aposentadorias e Pensões (CAPs). São destacados quatro elementos constitutivos do nascente sistema: iniciativa e forte ação normativa do Estado; financiamento tripartite, envolvendo também empresários e trabalhadores; acesso à assistência médica mediante filiação ao sistema; e o caráter assistencialista e excludente do seguro social nascente. A partir daí, a seqüência de criação de Caixas e Institutos que culminam na unificação, em 1966, com a o surgimento do Instituto Nacional de Previdência Social (INPS). Para Cohn, neste período coexistiram a forte pressão dos trabalhadores por ampliação e uniformização dos benefícios e intensa atividade normativa do Estado. Com a Lei Orgânica da Previdência Social, em 1960, esta uniformização foi acompanhada da incorporação da assistência médica individual ao sistema previdenciário e "...para a questão da saúde, foi nessa ocasião selada sua sorte privatizante e seu perfil cada vez mais distante das reais necessidades de saúde das clas- 
ses assalariadas e da população em geral" (p. 19). O processo, assinala Cohn, foi o de uma progressiva incorporação de benefícios, porém sob uma lógica assistencialista e controladora.

O momento da Constituição de 1988 representa uma inflexão no padrão de política previdenciária, pelos compromissos que expressa em termos de universalidade $\mathrm{e}$ eqüidade, e algumas inovações são assinaladas. Como diz: "Essas propostas representam uma mudança radical no quadro do sistema de proteção social brasileiro. Implementá-las, portanto, significa enfrentar o peso da tradição criada em todo o processo de sua montagem, exigindo maior racionalidade e agilidade do seu aparato institucional" (p. 29). Os obstáculos consistem em resgatar a credibilidade da burocracia previdenciária, ampliar o caráter público da gestão do sistema, rediscutir a cesta básica de serviços oferecidos e o acesso aos benefícios, e aprofundar a fiscalização aos acidentes de trabalho.

Um destaque importante no texto é conferido à Política de Saúde, cujo pano de fundo reside na descrição das profundas desigualdades sociais em nosso país. Apesar da lógica redistributiva embutida na Constituinte de 1988 e do sistema público de saúde instituído como caudatário da Reforma Sanitária,
Cohn atribui ao SUS certa incapacidade em superar a herança assistencialista, burocrática e privatista assentada no INAMPS. Assinala que o SUS permanece centralizado sob a égide do executivo federal; fortemente orientado ao mercado; dissociado das "reais necessidades de saúde da populaçāo brasileira"; com baixos investimentos; e "profundamente discriminatório e injusto".

O capítulo apresenta, de forma bastante clara e objetiva, as informações centrais para o acompanhamento da montagem da seguridade social no Brasil, e suas repercussões sobre o setor saúde. O conjunto tem o intuito, para além de instruir, intervir no debate atual do SUS, cujas orientações normativas decorrem da Constituinte e são confrontadas com o quadro de crise vigente. Desta forma, Cohn designa as diretrizes que, a seu ver, devem nortear tal intervenção. Destas, destacam-se: subordinação aos princípios gerais do SUS; descentralização, com efetiva transferência de recursos decisórios e financeiros às esferas locais; combate ao clientelismo nas relações intergovernamentais; reforma do Ministério da Saúde (MS) enquanto coordenador do sistema; maior controle sobre o desempenho orçamentário em função da multiplicidade de fontes; melhor articulação entre as dinâmicas dos Con- selhos de Saúde nos níveis municipal, estadual e nacional; e consolidar o papel do MS no âmbito da cooperação técnica e da pesquisa.

Por fim, demonstra preocupação com o fato de o debate acerca da absorção pela Seguridade Social dos direitos e benefícios ampliados pela Constituinte de 1988 , estar centrado na escassez de recursos. Como diz a Autora, "...a discussão mais acalorada se dá no seio dos setores mais organizados da sociedade, a questão de fundo que permanece é como de fato cumprir os preceitos constitu. cionais que ditam a universalização do acesso de todo e qualquer cidadāo a benefícios e serviços sociais essenciais, independentemente da sua inserção no mercado de trabalho e de seu nível de renda" (p. 54).

O segundo texto, "Estrutura e Organização da Atenção à Saúde no Brasil", foi escrito por Paulo Elias, e move-se pelo mesmo intuito de ressaltar as virtudes redistributivas do Estado e a vocação especial das políticas de saúde em apontar para a justiça social. Converge, também, em apontar o caráter iníqüo de sua implementação na realidade brasileira, acentuado pela chamada "onda neoliberal". Baseando-se em informes do Banco Mundial, o Autor ressalta a importância dos gastos em saúde no mundo e o perfil restritivo 
observado nos países da América Latina, por comparação aos mercados mais consolidados. Após uma rápida contextualização das políticas de saúde, Elias volta-se para o seu objetivo central - descrever mais detalhadamente o SUS, o que é feito de forma bastante didática, e oferecer diretrizes de superação dos problemas observados.

O Sistema de Saúde é mostrado em sua diversidade e conflitos de competências e atribuições, sendo a dinâmica público/privado seu pano de fundo. Os serviços públicos, a cargo das esferas de governo, recorrem à compra de serviços a terceiros, para além da rede própria assistencial, voltam-se "para os grupos sociais de renda média para baixo". Os serviços privados respondem pela cobertura "de $22 \%$ da população, em grande parte residente nas regiōes Sul e Sudeste do país" e, como assinala, volta-se "para os grupos de renda mais elevada e parcela dos trabalhadores urbanos das atividades industriais e de serviços pertencentes ao setor mais dinâmico da economia" (p. 68). Tudo isto contribui para a segmentação do sistema. As atenções do Autor voltam-se para o setor público, o qual é descrito com detalhes em suas diferentes formas, através da caracterização dos serviços. Este conjunto de prestadores, públicos e privados, distribuem-se entre postos de saúde, centros de saúde, unidades mistas, policlínicas, pronto-socorros e hospitais. Há maior detalhamento na descrição da rede em São Paulo, com tabelas sobre oferta de serviços e distribuição da força de trabalho.

O tema do financiamento é abordado e o seu caráter regressivo é denunciado, consoante com o texto anterior na qualificação do padrão injusto das políticas sociais no Brasil. Como diz, "Esta estrutura brasileira de incentivos com as características apresentadas resulta em subvenções altamente regressivas, destinando-se apenas às parcelas minoritárias da popu. lação de maior poder aquisitivo" (p. 94). Igualmente, os gastos em saúde no Brasil são analisados através de dados do Banco Mundial. Em que pesem as restrições que possam ser feitas à consistência destes dados e à sua capacidade de detectar o gasto público realmente praticado, distribuídos pelo emaranhado de rubricas na orçamentação pública das esferas de governo e das isenções fiscais, as fontes citadas por Elias são as usualmente utilizadas na literatura da área da saúcle e apontam para um descompasso entre necessidades sociais e gasto público.

Por fim, o Autor trata do tema da descentralização, vinculando-o, na origem, ao surgimento das Ações Integradas de Saúde, em 1983, nos "estertores do autoritarismo". Aponta muito adequadamente para a interação entre descentralização e pactuação, especialmente a partir da NOB-SUS 93, com o surgimento dos organismos colegiados intergovernamentais - as comissões intergestoras em níveis estadual e federal. Os Conselhos de Saúde, erigidos sob indução da Constituição Federal, constituem o "outro pilar da descentralização". Elias faz um reparo à aplicação do conceito de controle social à atividade dos conselhos, preferindo a idéia de controle público, o qual supõe "a participação direta dos cidadãos com poder deliberativo e a participaçāo representativa através dos canais institucionais tradicionais da democracia política: o voto, o Legislativo controlando e normalizando o Executivo, os partidos políticos representando os diversos interesses" (p. 115).

Ao longo de ambas as partes que compõem o livro, emergem duas constatações. Por um lado, uma profunda crença no potencial redistributivo das políticas públicas e, por outro, uma constatação dos Autores quanto ao perfil restritivo, concentrador e injusto observado no Brasil.

A contribuição de Amélia Cohn e de Paulo Elias ao debate da Seguridade no 
Brasil chega em um momento especialmente crítico. Após uma nova mudança de Ministro da Saúde, o SUS entra em uma fase de definições. Os avanços observados na NOB96, em termos de planejamento pactuado, de indução à ampliação dos papéis dos Conselhos de Saúde e de fortalecimento de organismos colegiados, como as comissões intergestoras, são confrontados com o risco da segmentação de clientelas através da focalização de políticas, no processo em curso. Quanto ao conjunto da Seguridade Social, a sua face mais poderosa, a Previdência Social, é hoje objeto de uma reforma que está tramitando no Congresso Nacional. Os termos da Reforma da Previdência envolvem a definição de áreas de atuação de sistemas complementares públicos e/ou privados; mudanças no teto de contribuição, nas faixas etárias de aposentadoria, na caracterização das aposentadorias espe- ciais, entre outros. Ou seja, estamos vivendo o momento da repactuação da solidariedade social, que o conjunto de direitos, benefícios e responsabilidades descritos ná Previdência Social espelha. São tempos de reformas influenciadas por um ambiente político distinto do que originou arranjos do Estado de Bem-Estar, e que exigem um grande espírito inovador daqueles que confiam no Estado como esfera privilegiada para promover a justiça social. 